OPEN ACCESS

Edited by:

Dietmar Funck,

University of Konstanz, Germany

Reviewed by:

Helena Storchova,

Institute of Experimental Botany Academy of Sciences of the Czech

Republic, Czech Republic

Ewa Sobieszczuk-Nowicka,

Adam Mickiewicz University, Poland

${ }^{*}$ Correspondence:

Donald F. Becker,

Redox Biology Center, Department

of Biochemistry, University

of Nebraska-Lincoln, N258 Beadle

Center, Lincoln, NE 68588, USA

dbecker3@unl.edu

Specialty section:

This article was submitted to Plant Physiology,

a section of the journal

Frontiers in Plant Science

Received: 14 May 2015

Accepted: 06 July 2015

Published: 22 July 2015

Citation:

Zhang L and Becker DF (2015) Connecting proline metabolism and signaling pathways in plant

senescence.

Front. Plant Sci. 6:552.

doi: 10.3389/fpls.2015.00552

\section{Connecting proline metabolism and signaling pathways in plant senescence}

\author{
Lu Zhang and Donald F. Becker \\ Redox Biology Center, Department of Biochemistry, University of Nebraska-Lincoln, Lincoln, NE, USA
}

The amino acid proline has a unique biological role in stress adaptation. Proline metabolism is manipulated under stress by multiple and complex regulatory pathways and can profoundly influence cell death and survival in microorganisms, plants, and animals. Though the effects of proline are mediated by diverse signaling pathways, a common theme appears to be the generation of reactive oxygen species (ROS) due to proline oxidation being coupled to the respiratory electron transport chain. Considerable research has been devoted to understand how plants exploit proline metabolism in response to abiotic and biotic stress. Here, we review potential mechanisms by which proline metabolism influences plant senescence, namely in the petal and leaf. Recent studies of petal senescence suggest proline content is manipulated to meet energy demands of senescing cells. In the flower and leaf, proline metabolism may influence ROS signaling pathways that delay senescence progression. Future studies focusing on the mechanisms by which proline metabolic shifts occur during senescence may lead to novel methods to rescue crops under stress and to preserve post-harvest agricultural products.

Keywords: proline, proline dehydrogenase, ${ }^{1} \Delta$-pyrroline-5-carboxylate synthetase, plant senescence, reactive oxygen species

\section{Introduction}

Proline metabolism involves the interconversion of proline and glutamate, a process linked to cellular energetics directly via the respiratory electron transport chain. Proline in higher plants is synthesized from glutamate and ornithine (Fichman et al., 2014). Glutamate-derived proline requires the bifunctional enzyme ${ }^{1} \Delta$-pyrroline-5-carboxylate (P5C) synthetase (P5CS), which catalyzes a twostep reaction requiring ATP and NADPH to generate glutamate- $\gamma$-semialdehyde (GSA; Figure 1). GSA spontaneously cyclizes to $\mathrm{P} 5 \mathrm{C}$ which is then reduced to proline in a NADPH dependent reaction catalyzed by P5C reductase (P5CR) (P5CR; At5g14800; Liang et al., 2013). In higher plant, P5CS, the rate-limiting enzyme of proline biosynthesis, has two isoforms, P5CS1 (At2g39800) and P5CS2 (At3g55610). P5CS1, localized in the chloroplast, is responsible for stress-induced proline synthesis (Liu et al., 2012a) whereas P5CS2, localized in the cytosol, is important for embryo development (Szekely et al., 2008; Funck et al., 2012). Ornithine-derived proline requires ornithine$\delta$-aminotransferase, which converts ornithine into GSA (Funck et al., 2008; Fichman et al., 2014).

The oxidation of proline to glutamate involves two mitochondrial enzymes, the flavin-dependent proline dehydrogenase (PRODH) and $\mathrm{NAD}^{+}$-dependent $\mathrm{P} 5 \mathrm{C}$ dehydrogenase (P5CDH) (P5CDH; At5g62530; Figure 1; Liang et al., 2013). PRODH catalyzes the rate-determining step of proline catabolism and in plants exists as two isoforms, PRODH1 (At3g30775) and PRODH2 (At5g38710). A search of available plant genomes indicates that the two PRODH isoforms are commonly 


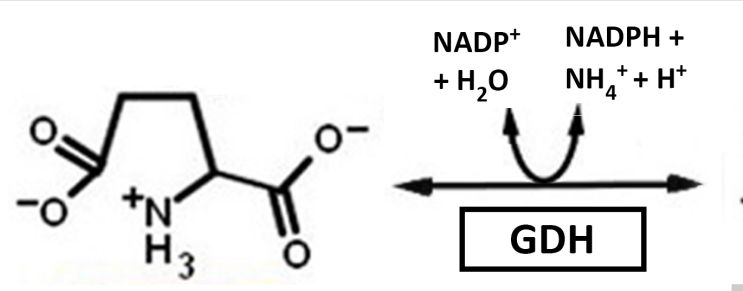

Glutamate

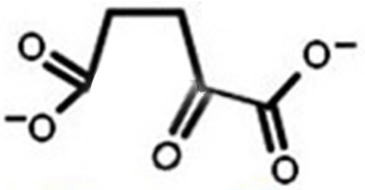

$\alpha$-Ketoglutarate

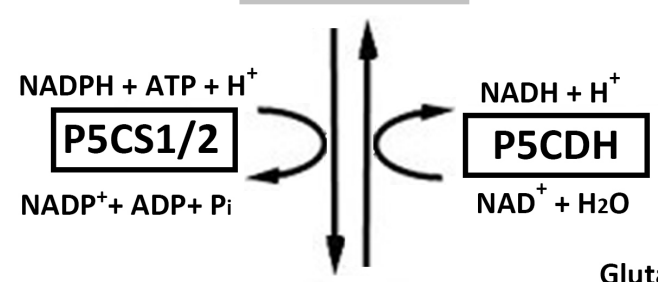<smiles>O=C1CCC(C(=O)[O-])[NH2+]1</smiles>

GSA<smiles>CC(=O)O</smiles>

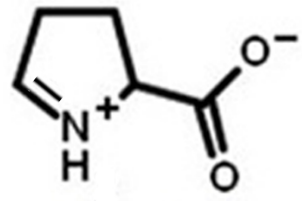

P5C
Glutamate $\alpha$-Ketoglutarate

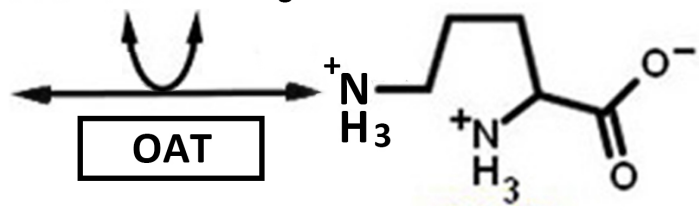

Ornithine
FIGURE 1 | Proline metabolic pathways in higher plants. In the biosynthesis pathway, ornithine and glutamate can be converted to glutamate- $\gamma$-semialdehyde (GSA) by ornithine- $\delta$-aminotransferase (OAT) and ${ }^{1} \Delta$-pyrroline-5-carboxylate (P5C) synthetase (P5CS), respectively. GSA can then spontaneously cyclize to P5C by losing one molecule of $\mathrm{H}_{2}$ O. P5C is the substrate for P5C reductase (P5CR), which catalyzes the last step in proline synthesis. In the catabolic pathway, proline

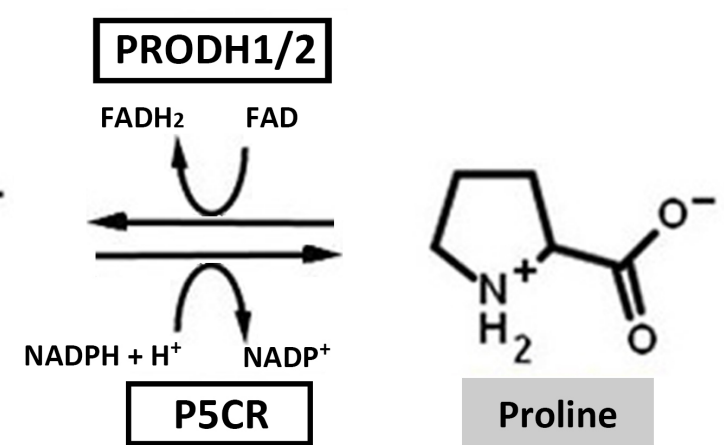

dehydrogenase $(\mathrm{PRODH})$ and $\mathrm{P} 5 \mathrm{C}$ dehydrogenase $(\mathrm{P} 5 \mathrm{CDH})$ catalyze the oxidation of proline to glutamate. Electrons from reduced flavin $\left(F A D H_{2}\right)$ are transferred to the respiratory electron transport chain to regenerate oxidized flavin (FAD) and complete the PRODH catalytic cycle. Glutamate dehydrogenase $(\mathrm{GDH})$ interconverts glutamate and $\alpha$-ketoglutarate, which enters the tricarboxylic acid cycle. Higher plants harbor two isoforms of P5CS and PRODH. found in higher plants. PRODH1 is ubiquitously expressed in plant whereas $P R O D H 2$ expression is localized to the vasculature (Funck et al., 2010). Proline oxidation yields approximately 30 ATP due to coupling with the mitochondrial electron transport chain and glutamate entering the tricarboxylic acid cycle as $\alpha$ ketoglutarate (Verbruggen and Hermans, 2008).

Besides its proteogenic function, proline has roles in energy utilization (Hare and Cress, 1997), reactive oxygen species (ROS) generation (Donald et al., 2001; Szekely et al., 2008; Liu et al., 2012b), programmed cell death (PCD; Donald et al., 2001; Liu et al., 2012b), unfolded protein response (Liang et al., 2014), cell reprogramming and development (Pistollato et al., 2010; Funck et al., 2012; D’Aniello et al., 2015), stress resistance (Strizhov et al., 1997; Krishnan et al., 2008; Szekely et al., 2008; Szabados and Savoure, 2010), and aging (Zarse et al., 2012; Pang and Curran, 2014). In plants, proline metabolism has been proposed to provide stress protection by helping maintain $\mathrm{NADPH} / \mathrm{NADP}^{+}$balance, GSH levels, and during pathogen infection, drive the oxidative 
burst of the hypersensitive response (HR; Miller et al., 2009; Ben Rejeb et al., 2014). Of interest to us are mechanisms by which proline influences the senescence process. Here, we review evidence for proline metabolism having a role in plant petal and leaf senescence.

\section{Proline in Senescing Petals: Energy Depletion and ROS Accumulation}

Senescence is initiated in flowers by natural aging, pollination, and detachment, and culminates in PCD (Rogers, 2012, 2013). Petals, one of the non-productive organs of flowers undergoing senescence (Rogers, 2012), are not photosynthetic (Rogers, 2013). Petals commonly serve as nutrient sinks during development and typically exhibit energy depletion during late stages of senescence (Rogers, 2013). Here, we discuss proline metabolism in the senescing petal of cut flowers.

Studies of flowers have revealed that proline metabolism may have several impacts on petal senescence. A 14-fold increase in proline content was found in petals of cut roses (Rosa hybrid) during senescence (Kumar et al., 2009). In rose petals, increased activity of P5CS and PRODH was observed during senescence progression. P5CS activity was generally higher than PRODH at different stages of senescence (Kumar et al., 2009). The elevated P5CS activity indicates that higher proline content was primarily due to biosynthesis from glutamate (Kumar et al., 2009). Glutamate can be generated by coordinated glutamine synthetase (GS) and glutamine oxoglutarate aminotransferase activity at early stages of senescence and, at late-senescence, by glutamate dehydrogenase (GDH; Figure 1; Kumar et al., 2009). The rise in proline content during senescence may be triggered by lower water potential as senescing rose petals were found to have decreased water potential and elevated levels of the stress hormone abscisic acid (ABA; Kumar et al., 2008), a signaling molecule that induces proline biosynthesis during stress (Savoure et al., 1997; Strizhov et al., 1997). It has not yet been fully explored whether increased proline content facilitates petal senescence or is only a consequence of senescence. Interestingly, at complete flower senescence proline levels dropped by $50 \%$ suggesting that loss of endogenous proline correlates with the end of senescence and termination of vase life. Exogenous application of proline to petals was thus suggested as a possible approach for extending vase life (Kumar et al., 2009).

Because flowers are heterotrophic, increased PRODH activity likely unleashes proline as a fuel source for ATP production during petal senescence. In cut tulips (Tulipa gesneriana), ATP content in petals drops dramatically at day one of flower opening (Azad et al., 2008). Sucrose supplementation, which helps maintain ATP levels, increases vase life indicating the importance of ATP production (Azad et al., 2008). Evidence supporting utilization of proline during senescence was shown by treatment of carnations (Dianthus caryophyllus) with aminooxyacetic acid, an inhibitor of ethylene biosynthesis (Yakimova et al., 1997). Aminooxyacetic acid extended vase life, which correlated with a $40 \%$ decrease in endogenous proline content of senescing petals compared to untreated flowers (Yakimova et al., 1997). Also, application of the plant hormone salicylic acid (SA) to lisianthus flowers (Eustoma grandiflorum Mariachi) doubled the vase life, which correlated with a 75\% reduction in proline content (Kazemi et al., 2011). It is possible that the lower proline content observed with SA treatment is due to increased PRODH activity in the petals. In leaves of Arabidopsis, exogenous application of SA activates transcription of PRODH1 (Cecchini et al., 2011). Whether SA also increases PRODH activity in flower petals needs to be confirmed. Application of $5 \mathrm{mM}$ proline extended the vase life of Rosa hybrida by 30\%, resulting in higher endogenous proline content and PRODH levels (Kumar et al., 2010). Altogether, the results from different studies suggest that proline catabolism and exogenous proline treatment may delay petal senescence by preventing depletion of ATP.

The benefit of proline catabolism during energy-depleted conditions is well known in other organisms and, in worms has been linked to the aging process. For example, in the Caenorhabditis elegans daf-2 mutant, AAK-2 (AMP-activated kinase, AMPK) upregulates $P R O D H$, which is proposed to facilitate lifespan extension by replenishing ATP levels and generating ROS as a signaling molecule to induce antioxidant defenses (Zarse et al., 2012). The AMPK homolog in plants is SnRK1 (sucrose-non-fermenting-1-related protein kinase-1), which regulates members of the S1 basic leucine zipper (bZIP) transcription family, such as bZIP1, bZIP11, and bZIP53, under low sugar or energy conditions (Polge and Thomas, 2007; Tome et al., 2014). bZIP11 is expressed more abundantly in petals (Hummel et al., 2009) relative to bZIP1 and dZIP53 (Llorca et al., 2014). Overexpression of bZIP11 resulted in decreased proline content consistent with upregulation of proline catabolism (Hanson et al., 2008). In Arabidopsis, expression of PRODH2 in the vascular tissue and abscission zone of petals is regulated by bZIP11 (Hanson et al., 2008) whereas PRODH1 expression is induced by bZIP1 and bZIP53 (Dietrich et al., 2011). Thus, in response to low sucrose, expression levels of $d Z I P 1, b Z I P 11$, and $b Z I P 53$ increase, resulting in higher expression of $P R O D H 1$ and $P R O D H 2$ thereby increasing proline catabolic flux (Funck et al., 2010; Llorca et al., 2014).

Is regulation of PRODH by bZIPs relevant to senescence? A role for SnRK1 and bZIPs in senescence is supported by different studies. For example, disruption of SnRK1 was shown to accelerate senescence progression in moss (Physcomitrella patens, Polge and Thomas, 2007). The expression of bZIP1 and bZIP53 in Arabidopsis are upregulated during dark-induced leaf senescence (Dietrich et al., 2011). PRODH1, regulated by bZIP1 and bZIP53, is the dominant isoform in flowers under most conditions (Funck et al., 2010). Therefore, bZIP1, bZIP53, and PRODH1, may have important roles in the mechanism by which SnRK1 influences the senescence of cut flowers. More direct evidence is needed to establish whether PRODH1 and PRODH2 have a critical role in senescence delay via the SnRK1 signaling pathway.

Besides energy depletion, another important factor of senescence is the accumulation of oxidative damage in aging tissue. Studies have shown that ROS accumulation plays a vital role in flower senescence as reviewed by Rogers (2012). ROS appears to facilitate the aging process and is necessary for petal senescence. $\mathrm{H}_{2} \mathrm{O}_{2}$ was found to buildup in daylilies (Hemerocallis) during senescence progression (Chakrabarty 
et al., 2009). In Tulipa gesneriana, rising $\mathrm{H}_{2} \mathrm{O}_{2}$ levels followed the appearance of senescence markers (protease activity and cytochrome c) at the end of flower opening (Azad et al., 2008). To alleviate the oxidative burden in snapdragon (Antirrhinum majus) petals, ascorbic acid was applied as an exogenous antioxidant resulting in a $20 \%$ longer vase life relative to untreated flowers (Abdulrahman et al., 2012).

Proline is known to protect against oxidative stress in many organisms including fungi (Chen and Dickman, 2005; Chen et al., 2006), bacteria (Zhang et al., 2015), plants (Szabados and Savoure, 2010; Sorkheh et al., 2012), and to animals (Natarajan et al., 2012; Zarse et al., 2012). It is still controversial, however, whether protection is due to proline directly scavenging ROS. Proline is expected to efficiently react with ${ }^{\bullet} \mathrm{OH}$ (Signorelli et al., 2014) and was suggested to scavenge ${ }^{1} \mathrm{O}_{2}$ (Alia et al., 2001). Another study, however, reported that proline does not quench ${ }^{1} \mathrm{O}_{2}$ in plants (Signorelli et al., 2013) and recently, proline was found not to directly scavenge $\mathrm{H}_{2} \mathrm{O}_{2}$ (Zhang et al., 2015). In bacteria and mammalian cells, $\mathrm{PRODH}$ is necessary for prolinemediated adaptation to oxidative stress (Natarajan et al., 2012; Zhang et al., 2015). Proline catabolism generates $\mathrm{H}_{2} \mathrm{O}_{2}$ as a by-product thereby activating antioxidant signaling pathways. Proline oxidation induces the OxyR regulon of Escherichia coli (Zhang et al., 2015), Akt pathway in human cells (Natarajan et al., 2012), and the MAPK pathway (Okuyama et al., 2010) in the C. elegans daf-2 mutant (Zarse et al., 2012). Thus, although the signaling pathways vary, $\mathrm{H}_{2} \mathrm{O}_{2}$ production by proline catabolism seems to be a conserved mechanism by which proline influences antioxidant defenses.

Could proline metabolism influence ROS accumulation during senescence? Interestingly, relative to untreated roses, proline treatment sustained $\mathrm{Mn}$-dependent superoxide dismutase (MnSOD) activity, the dominant SOD in petals, resulting in twofold lower levels of superoxide anion radicals at each stage of petal senescence (Kumar et al., 2010). In plant, MAPK cascades respond to ROS and regulate antioxidant signaling pathways (Pitzschke et al., 2009; Sinha et al., 2011). MAPK cascades consist of three kinases: MAPK kinase kinases (MEKKs), MAPK kinases (MKKs) and MAPKs (MPKs; Sinha et al., 2011). $\mathrm{H}_{2} \mathrm{O}_{2}$ activates ROS scavenging enzymes by initiating a phosphorylation cascade involving MKK4/5 and MPK3/6 (Kovtun et al., 2000). MKK4 and MKK5 are known to be necessary for flower organ abscission in Arabidopsis (Cho et al., 2008). Tandem RNAi knockdown of both $M K K 4$ and MKK5 showed a defect in petal abscission, although individual RNAi knockdown of either gene had a normal phenotype (Cho et al., 2008). MPK3 and MPK6 were also required for petal abscission (Cho et al., 2008). Future studies are needed to understand whether ROS triggers the phosphorylation of MKK4/5 and MPK3/6 during petal senescence thereby promoting petal abscission.

Little is known about the relationship between PRODH and the MAPK pathway in plants, however, hypoosmotic stress was observed to induce a similar pattern of MPK20 and PRODH expression in Arabidopsis, suggesting a link between PRODH and MPK20 (Moustafa et al., 2008). A recent genomic study showed MPK20 was highly induced by $\mathrm{H}_{2} \mathrm{O}_{2}$ stress in cotton (Gossypium raimondii, Zhang et al., 2014). Is it plausible that ROS generated by proline metabolism induces MPK20 during petal senescence? Stronger evidence is available for linking proline biosynthesis with MAPK signaling, namely MKK4. Overexpression of ZmMKK4, a gene from Zea mays, in tobacco or Arabidopsis resulted in elevated P5CS2 activity (Kong et al., 2011a), leading to increased proline content and tolerance to hyperosmotic stress (Kong et al., 2011a,b). In line with the ROS sensing role of the MAPK signaling pathway, overexpression of $Z m M K K 4$ resulted in higher peroxidase activity and lower ROS levels (Kong et al., 2011a,b). Whether MKK4 also upregulates P5CS during flower senescence needs to be determined.

\section{Proline in Leaf Senescence: Upregulation of Proline Catabolism and Hormone-Induced Pathways}

Leaf senescence, a developmentally regulated PCD, is agedependent and induced by environmental signals (drought, detachment or darkness; Smart, 1994; van Doorn and Woltering, 2004). The role of proline metabolism in leaf senescence shares some similarities with petals but also has unique features (Price et al., 2008). Proline levels increase proportionally with leaf age in excised leaf segments and are an indicator of leaf senescence (Wang et al., 1982; Mondal et al., 1985). Unlike flowers, leaf generates energy via photosynthesis which is maintained during late stages of senescence (Smart, 1994; Kotakis et al., 2014). Thus, proline is not needed as an energy source during leaf senescence.

What are the relevant mechanisms of proline metabolism in leaf senescence? One observation is that during natural leaf aging proline catabolism appears to be upregulated via increased expression of $\mathrm{PRODH} 2$ and $\mathrm{P} 5 \mathrm{CDH}$. In Arabidopsis thaliana and Brassica napus (rapeseed), $\mathrm{PRODH} 2$ expression was strongly induced in the course of natural leaf aging (Funck et al., 2010; Faes et al., 2015), whereas PRODH1 expression was moderately upregulated (Funck et al., 2010). P5CDH expression was also reported to increase in older leaves of Arabidopsis (Deuschle et al., 2004). Why proline catabolism would be upregulated during natural leaf senescence remains largely unresolved since there does not seem to be a significant energy deficit as mentioned above. Proline degradation, however, may assist nitrogen recycling in the phloem from old leaves to sink organs (Faes et al., 2015) which would be consistent with the stronger expression of $\mathrm{PRODH} 2$ in vascular tissues at senescence. Cytosolic GS1 and GDH are also induced during leaf senescence, apparently to facilitate nitrogen recycling (Masclaux-Daubresse et al., 2005). In fact, proline treatment of Arabidopsis was observed to induce expression of GS1 and GDH (Masclaux-Daubresse et al., 2005), indicating that proline catabolism provides glutamate as a substrate for GS1 and GDH. Thus, proline may be needed for nitrogen cycling during leaf senescence.

The possibility of PRODH1 being involved in plant hormone induced senescence is inferred from a recent study showing proline metabolism is regulated by phosphatidylinositol-3,4,5triphosphate dependent kinase (PI3K; Leprince et al., 2015). 


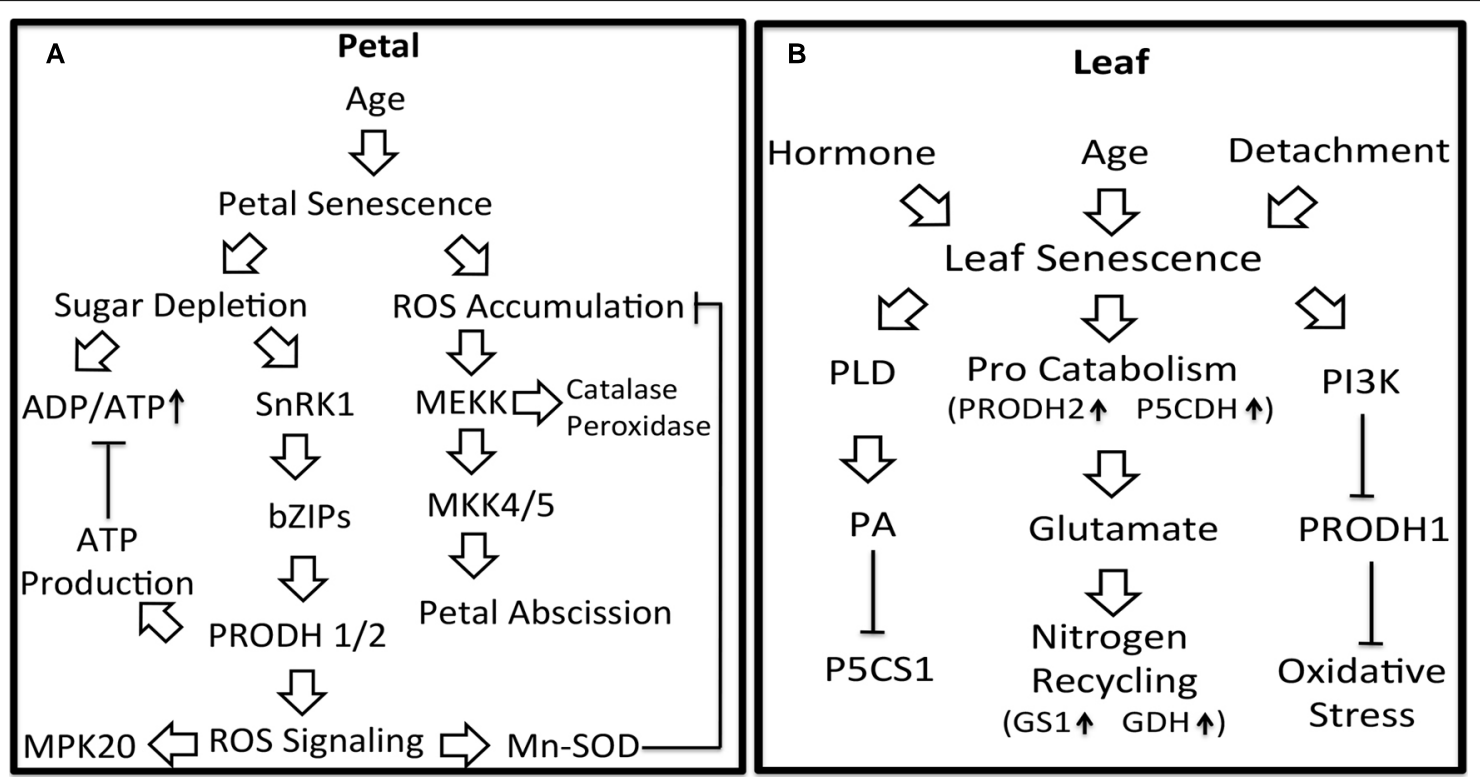

FIGURE 2 | Potential linkages between proline metabolism and signaling pathways in petal and leaf senescence. Petal senescence (A): Aging induced petal senescence results in ROS accumulation and sugar depletion. SnRK1, activated in response to depleted sugar, is proposed to induce PRODH1/2 expression via bZIP1, bZIP11, and bZIP53. Upregulation of $P R O D H 1 / 2$ expression would be predicted to generate ATP thereby attenuating increases in ADP/ATP. PRODH activity is also expected to generate ROS as a by-product, possibly leading to activation of MPK2O and increased Mn-SOD activity. Enhanced Mn-SOD activity would help diminish accumulated ROS and oxidative damage during petal senescence. Activation of MAPK pathways by ROS would induce expression of antioxidant enzymes and petal abscission. Leaf senescence (B): Leaf senescence can be induced by plant hormones, age and detachment. During age-related senescence, the expression of $P R O D H 2$ and $\mathrm{P} 5 \mathrm{CDH}$ are induced, suggesting a higher flux of proline catabolism and more glutamate available for nitrogen recycling. In response to $\mathrm{H}_{2} \mathrm{O}_{2}$ during hormone-induced senescence, $\mathrm{PI} 3 \mathrm{~K}$ may down-regulate $\mathrm{PRODH} 1$ resulting in less ROS signaling and adaptation to oxidative stress. Also during hormone-induced senescence, phospholipase D (PLD) and its product phosphatidic acid (PA) inhibit P5CS1 expression.
Under salt stress, inhibition of PI3K by LY294002 resulted in lower P5CS1 and higher PRODH1 expression and, decreased proline content in Arabidopsis (Leprince et al., 2015). PRODH1 expression was also higher in a pi3k-hemizygous Arabidopsis mutant (Leprince et al., 2015). Thus, PI3K appears to repress PRODH1 expression. The mechanism by which plant hormones such as methyl jasmonic-acid (JA; Hung et al., 2006) and ABA (Hung and Kao, 2005) induce senescence, involves PI3K signaling and $\mathrm{H}_{2} \mathrm{O}_{2}$. Inhibiting PI3K activity with LY294002 aborted $\mathrm{H}_{2} \mathrm{O}_{2}$ production and delayed JA induced-senescence in rice leaves (Hung et al., 2006). Phosphatidylinositol-3-phosphate (PI3P), the product of $\mathrm{PI} 3 \mathrm{~K}$, has also been shown to be necessary for ABAinduced $\mathrm{H}_{2} \mathrm{O}_{2}$ production and senescence (Hung and Kao, 2005). Thus, $\mathrm{PI} 3 \mathrm{~K}$ and PI3P promote plant hormone-induced senescence via $\mathrm{H}_{2} \mathrm{O}_{2}$ production. Repression of $P R O D H 1$ by $\mathrm{PI} 3 \mathrm{~K}$ could potentially increase oxidative stress burden as discussed above due to loss of proline-mediated ROS signaling and decreased antioxidant defense.

Additional evidence for proline metabolism being involved in plant hormone-induced senescence is from studies of lipid degradation. Lipid degradation is generally upregulated during leaf senescence due to loss of cellular membrane integrity (Lim et al., 2007). Phospholipase D (PLD) catalyzes the production of membrane-bound phosphatidic acid (PA) from phospholipid (Kolesnikov et al., 2012). PLD activity has been shown to gradually increase at senescence in castor oil plant (Ricinus communis) leaves (Ryu and Wang, 1995). Plants harbor three isoforms of PLDs: PLD $\alpha, \operatorname{PLD} \beta$ and PLD $\delta$ (Kolesnikov et al., 2012). Antisense suppression of $P L D \alpha$, the most abundant PLD, slowed down ABAand ethylene-induced senescence of detached Arabidopsis leaves, while there was no effect on natural aging leaf senescence (Fan et al., 1997). The suppression of $P L D \delta$, which is upregulated during senescence, also delays ABA-promoted senescence in Arabidopsis (Jia et al., 2013). PLD appears to be a negative regulator of P5CS1 as inhibition of PA signaling by 1-butanol was observed to increase P5CS1 expression in Arabidopsis (Thiery et al., 2004) and Thellungiella halophila (Ghars et al., 2012). Because senescence-specific degradation of Calvin cycle enzymes has been shown to lower $\mathrm{NADP}^{+}$levels in chloroplasts (Zhang et al., 2012) increased P5CS1 expression may help maintain $\mathrm{NADPH} / \mathrm{NADP}^{+}$balance (Liang et al., 2013). Whether regulation of P5CS1 by PA signaling is important during hormone-induced leaf senescence needs to be determined.

\section{Summary and Future Direction}

The various roles of proline metabolism in energetics, ROS signaling, and cellular processes continue to unfold (Ben Rejeb et al., 2014). Proline metabolic ROS production appears to be a general phenomenon in diverse organisms potentially impacting cellular processes such as aging and plant senescence. An excellent example of PRODH mediated ROS production in plants is from 
studies of Pseudomonas syringae pathogen induced HR (Cecchini et al., 2011). In the late stages of $\mathrm{HR}, P R O D H$ and P5CDH expression becomes uncoupled, thereby enabling proline/P5C cycling via PRODH and P5CR, leading to an oxidative burst (Cecchini et al., 2011; Monteoliva et al., 2014).

The molecular pathways by which proline metabolism is regulated during plant senescence are summarized in Figure 2. The ability of proline to delay senescence in petal and leaf tissues is likely due to protection against oxidative stress that occurs in the aging tissue. In leaf, proline may help redistribute nitrogen to younger tissue whereas in flowers, proline helps counter energy shortages. Further insights into how proline metabolism impacts petal and leaf senescence will require

\section{References}

Abdulrahman, Y. A., Ali, S. F., and Faizi, H. S. (2012). Effect of sucrose and ascorbic acid concentrations on vase life of snapdragon (Antirrhinum Majus L.) cut flowers. Int. J. Pure Appl. Sci. Technol. 13, 32-41.

Alia, Mohanty, P., and Matysik, J. (2001). Effect of proline on the production of singlet oxygen. Amino Acids 21, 195-200. doi: 10.1007/s007260170026

Azad, A. K., Ishikawa, T., Ishikawa, T., Sawa, Y., and Shibata, H. (2008). Intracellular energy depletion triggers programmed cell death during petal senescence in tulip. J. Exp. Bot. 59, 2085-2095. doi: 10.1093/jxb/ern066

Ben Rejeb, K., Abdelly, C., and Savoure, A. (2014). How reactive oxygen species and proline face stress together. Plant Physiol. Biochem. 80, 278-284. doi: 10.1016/j.plaphy.2014.04.007

Cecchini, N. M., Monteoliva, M. I., and Alvarez, M. E. (2011). Proline dehydrogenase contributes to pathogen defense in Arabidopsis. Plant Physiol. 155, 1947-1959. doi: 10.1104/pp.110.167163

Chakrabarty, D., Verma, A. K., and Datta, S. K. (2009). Oxidative stress and antioxidant activity as the basis of senescence in Hemerocallis (day lily) flowers. J. Hortic. For. 1, 113-119.

Chen, C., and Dickman, M. B. (2005). Proline suppresses apoptosis in the fungal pathogen Colletotrichum trifolii. Proc. Natl. Acad. Sci. U.S.A. 102, 3459-3464. doi: 10.1073/pnas.0407960102

Chen, C. B., Wanduragala, S., Becker, D. F., and Dickman, M. B. (2006). Tomato QM-Like protein protects Saccharomyces cerevisiae cells against oxidative stress by regulating intracellular proline levels. Appl. Environ. Microbiol. 72, 4001-4006. doi: 10.1128/Aem.02428-05

Cho, S. K., Larue, C. T., Chevalier, D., Wang, H., Jinn, T. L., Zhang, S., et al. (2008). Regulation of floral organ abscission in Arabidopsis thaliana. Proc. Natl. Acad. Sci. U.S.A. 105, 15629-15634. doi: 10.1073/pnas.0805539105

D’Aniello, C., Fico, A., Casalino, L., Guardiola, O., Di Napoli, G., Cermola, F., et al. (2015). A novel autoregulatory loop between the Gcn2-Atf4 pathway and LProline metabolism controls stem cell identity. Cell Death Differ. 22, 1094-1105. doi: $10.1038 /$ cdd.2015.24

Deuschle, K., Funck, D., Forlani, G., Stransky, H., Biehl, A., Leister, D., et al. (2004). The role of $\Delta^{1}$-pyrroline-5-carboxylate dehydrogenase in proline degradation. Plant Cell 16, 3413-3425. doi: 10.1105/tpc.104.023622

Dietrich, K., Weltmeier, F., Ehlert, A., Weiste, C., Stahl, M., Harter, K., et al. (2011). Heterodimers of the Arabidopsis transcription factors bZIP1 and bZIP 53 reprogram amino acid metabolism during low energy stress. Plant Cell 23, 381-395. doi: 10.1105/tpc.110. 075390

Donald, S. P., Sun, X. Y., Hu, C. A., Yu, J., Mei, J. M., Valle, D., et al. (2001). Proline oxidase, encoded by p53-induced gene- 6 , catalyzes the generation of proline-dependent reactive oxygen species. Cancer Res. 61, 1810-1815.

Faes, P., Deleu, C., Ainouche, A., Le Caherec, F., Montes, E., Clouet, V., et al. (2015). Molecular evolution and transcriptional regulation of the oilseed rape proline dehydrogenase genes suggest distinct roles of proline catabolism during development. Planta 241, 403-419. doi: 10.1007/s00425-014-2189-9

Fan, L., Zheng, S., and Wang, X. (1997). Antisense suppression of phospholipase $\mathrm{D} \alpha$ retards abscisic acid- and ethylene-promoted senescence of postharvest Arabidopsis leaves. Plant Cell 9, 2183-2196. doi: 10.1105/tpc.9.12.2183 additional studies that connect proline with plant senescence signaling pathways. Exploration of the linkages between proline metabolism and important pathways of plant senescence such as MAPK signaling, the SnRK1-bZIP pathway and PI3K signaling will be valuable targets for future study. Better understanding of proline metabolism in senescing leaves may uncover novel strategies for preserving post-harvest flowers and delaying stressinduced leaf senescence.

\section{Acknowledgment}

This research was supported in part by grants GM079393 and P30GM103335 from the National Institutes of Health.

Fichman, Y., Gerdes, S. Y., Kovacs, H., Szabados, L., Zilberstein, A., and Csonka, L. N. (2014). Evolution of proline biosynthesis: enzymology, bioinformatics, genetics, and transcriptional regulation. Biol. Rev. Camb. Philos. Soc. doi: 10.1111/brv.12146 [Epub ahead of print].

Funck, D., Eckard, S., and Muller, G. (2010). Non-redundant functions of two proline dehydrogenase isoforms in Arabidopsis. BMC Plant Biol. 10:70. doi: 10.1186/1471-2229-10-70

Funck, D., Stadelhofer, B., and Koch, W. (2008). Ornithine- $\delta$-aminotransferase is essential for arginine catabolism but not for proline biosynthesis. BMC Plant Biol. 8:40. doi: 10.1186/1471-2229-8-40

Funck, D., Winter, G., Baumgarten, L., and Forlani, G. (2012). Requirement of proline synthesis during Arabidopsis reproductive development. BMC Plant Biol. 12:191. doi: 10.1186/1471-2229-12-191

Ghars, M. A., Richard, L., Lefebvre-De Vos, D., Leprince, A. S., Parre, E., Bordenave, M., et al. (2012). Phospholipases C and D modulate proline accumulation in Thellungiella halophila/Salsuginea differently according to the severity of salt or hyperosmotic stress. Plant Cell Physiol. 53, 183-192. doi: 10.1093/pcp/ pcr164

Hanson, J., Hanssen, M., Wiese, A., Hendriks, M. M., and Smeekens, S. (2008). The sucrose regulated transcription factor bZIP11 affects amino acid metabolism by regulating the expression of ASPARAGINE SYNTHETASE1 and PROLINE DEHYDROGENASE2. Plant J. 53, 935-949. doi: 10.1111/j.1365313X.2007.03385.x

Hare, P. D., and Cress, W. A. (1997). Metabolic implications of stressinduced proline accumulation in plants. Plant Growth Regul. 21, 79-102. doi: 10.1023/A:1005703923347

Hummel, M., Rahmani, F., Smeekens, S., and Hanson, J. (2009). Sucrose-mediated translational control. Ann. Bot. 104, 1-7. doi: 10.1093/aob/mcp086

Hung, K. T., Hsu, Y. T., and Kao, C. H. (2006). Hydrogen peroxide is involved in methyl jasmonate-induced senescence of rice leaves. Physiol. Plant. 127, 293-303. doi: 10.1111/J.1399-3054.2006.00662.X

Hung, K. T., and Kao, C. H. (2005). Phosphatidylinositol 3-phosphate is required for abscisic acid-induced hydrogen peroxide production in rice leaves. Plant Growth Regul. 45, 95-101. doi: 10.1007/S10725-005-1434-4

Jia, Y., Tao, F., and Li, W. (2013). Lipid profiling demonstrates that suppressing Arabidopsis phospholipase D $\delta$ retards ABA-promoted leaf senescence by attenuating lipid degradation. PLoS ONE 8:e65687. doi: 10.1371/journal.pone.0065687

Kazemi, M., Aran, M., and Zamani, S. (2011). Extending the vase life of lisianthus (Eustoma grandiflorum mariachi. cv. blue) with different preservative. Am. J. Plant Physiol. 6, 167-175. doi: 10.3923/ajpp.2011.167.175

Kolesnikov, Y. S., Nokhrina, K. P., Kretynin, S. V., Volotovski, I. D., Martinec, J., Romanov, G. A., et al. (2012). Molecular structure of phospholipase D and regulatory mechanisms of its activity in plant and animal cells. Biochem. (Mosc.) 77, 1-14. doi: 10.1134/S0006297912010014

Kong, X. P., Pan, J. W., Zhang, M. Y., Xing, X., Zhou, Y., Liu, Y., et al. (2011a). $Z m M K K 4$, a novel group $\mathrm{C}$ mitogen-activated protein kinase kinase in maize (Zea mays), confers salt and cold tolerance in transgenic Arabidopsis. Plant Cell Environ. 34, 1291-1303. doi: 10.1111/J.1365-3040.2011.02329.X

Kong, X. P., Sun, L. P., Zhou, Y., Zhang, M. Y., Liu, Y., Pan, J. W., et al. (2011b). $Z m M K K 4$ regulates osmotic stress through reactive oxygen species scavenging 
in transgenic tobacco. Plant Cell Rep. 30, 2097-2104. doi: 10.1007/S00299-0111116-9

Kotakis, C., Kyzeridou, A., and Manetas, Y. (2014). Photosynthetic electron flow during leaf senescence: evidence for a preferential maintenance of photosystem I activity and increased cyclic electron flow. Photosynthetica 52, 413-420. doi: 10.1007/S11099-014-0046-5

Kovtun, Y., Chiu, W. L., Tena, G., and Sheen, J. (2000). Functional analysis of oxidative stress-activated mitogen-activated protein kinase cascade in plants. Proc. Natl. Acad. Sci. U.S.A. 97, 2940-2945. doi: 10.1073/pnas.97.6.2940

Krishnan, N., Dickman, M. B., and Becker, D. F. (2008). Proline modulates the intracellular redox environment and protects mammalian cells against oxidative stress. Free Radic. Biol. Med. 44, 671-681. doi: 10.1016/j.freeradbiomed.2007.10.054

Kumar, N., Pal, M., Singh, A., Sairam, R. K., and Srivastava, G. C. (2010). Exogenous proline alleviates oxidative stress and increase vase life in rose (Rosa hybrida $\mathrm{L}$ 'Grand Gala'). Sci. Hortic. 127, 79-85. doi: 10.1016/J.Scienta.2010.09.009

Kumar, N., Pal, M., and Srivastava, G. C. (2009). Proline metabolism in senescing rose petals (Rosa hybrida L. 'First Red'). J. Hortic. Sci. Biotech. 84, 536-540.

Kumar, N., Srivastava, G. C., and Dixit, K. (2008). Hormonal regulation of flower senescence in roses (Rosa hybrida L.). Plant Growth Regul. 55, 65-71. doi: 10.1007/S10725-008-9259-6

Leprince, A. S., Magalhaes, N., De Vos, D., Bordenave, M., Crilat, E., Clement, G., et al. (2015). Involvement of Phosphatidylinositol 3-kinase in the regulation of proline catabolism in Arabidopsis thaliana. Front. Plant Sci. 5:772. doi: 10.3389/Fpls.2014.00772

Liang, X., Dickman, M. B., and Becker, D. F. (2014). Proline biosynthesis is required for endoplasmic reticulum stress tolerance in Saccharomyces cerevisiae. J. Biol. Chem. 289, 27794-27806. doi: 10.1074/jbc.M114.562827

Liang, X., Zhang, L., Natarajan, S. K., and Becker, D. F. (2013). Proline mechanisms of stress survival. Antioxid. Redox Signal. 19, 998-1011. doi: 10.1089/ars.2012.5074

Lim, P. O., Kim, H. J., and Nam, H. G. (2007). Leaf senescence. Annu. Rev. Plant Biol. 58, 115-136. doi: 10.1146/annurev.arplant.57.032905.105316

Liu, P., Sun, F., Gao, R., and Dong, H. (2012a). RAP2.6L overexpression delays waterlogging induced premature senescence by increasing stomatal closure more than antioxidant enzyme activity. Plant Mol. Biol. 79, 609-622. doi: 10.1007/s11103-012-9936-8

Liu, W., Le, A., Hancock, C., Lane, A. N., Dang, C. V., Fan, T. W., et al. (2012b). Reprogramming of proline and glutamine metabolism contributes to the proliferative and metabolic responses regulated by oncogenic transcription factor c-MYC. Proc. Natl. Acad. Sci. U.S.A 109, 8983-8988. doi: $10.1073 /$ pnas.1203244109

Llorca, C. M., Potschin, M., and Zentgraf, U. (2014). bZIPs and WRKYs: two large transcription factor families executing two different functional strategies. Front. Plant Sci. 5:169. doi: 10.3389/Fpls.2014.00169

Masclaux-Daubresse, C., Carrayol, E., and Valadier, M. H. (2005). The two nitrogen mobilisation- and senescence-associated GS1 and GDH genes are controlled by $\mathrm{C}$ and N metabolites. Planta 221, 580-588. doi: 10.1007/s00425-004-1468-2

Miller, G., Honig, A., Stein, H., Suzuki, N., Mittler, R., and Zilberstein, A. (2009). Unraveling $\Delta^{1}$-pyrroline-5-carboxylate-proline cycle in plants by uncoupled expression of proline oxidation enzymes. J. Biol. Chem. 284, 26482-26492. doi: 10.1074/jbc.M109.009340

Mondal, W. A., Dey, B. B., and Choudhuri, M. A. (1985). Proline accumulation as a reliable indicator of monocarpic senescence in rice cultivars. Experientia 41, 346-348. doi: 10.1007/Bf02004497

Monteoliva, M. I., Rizzi, Y. S., Cecchini, N. M., Hajirezaei, M. R., and Alvarez, M. E. (2014). Context of action of proline dehydrogenase (ProDH) in the hypersensitive response of Arabidopsis. BMC Plant Biol. 14:21. doi: 10.1186/1471-2229-14-21

Moustafa, K., Lefebvre-De Vos, D., Leprince, A. S., Savoure, A., and Laurie 'Re, C. (2008). Analysis of the Arabidopsis mitogen-activated protein kinase families: organ specificity and transcriptional regulation upon water stresses. Sch. Res. Exch. 143658. doi: 10.3814/2008/143656

Natarajan, S. K., Zhu, W. D., Liang, X. W., Zhang, L., Demers, A. J., Zimmerman, M. C., et al. (2012). Proline dehydrogenase is essential for proline protection against hydrogen peroxide-induced cell death. Free Radic. Bio. Med. 53, 1181-1191. doi: 10.1016/J.Freeradbiomed.2012.07.002

Okuyama, T., Inoue, H., Ookuma, S., Satoh, T., Kano, K., Honjoh, S., et al. (2010). The ERK-MAPK pathway regulates longevity through SKN-1 and insulin-like signaling in Caenorhabditis elegans. J. Biol. Chem. 285, 30274-30281. doi: 10.1074/Jbc.M110.146274

Pang, S., and Curran, S. P. (2014). Adaptive capacity to bacterial diet modulates aging in C. elegans. Cell Metab. 19, 221-231. doi: 10.1016/j.cmet.2013.12.005

Pistollato, F., Persano, L., Rampazzo, E., and Basso, G. (2010). L-Proline as a modulator of ectodermal differentiation in ES cells. Focus on "L-Proline induces differentiation of ES cells: a novel role for an amino acid in the regulation of pluripotent cells in culture. Am. J. Physiol. Cell Physiol. 298, C979-C981. doi: 10.1152/ajpcell.00072.2010

Pitzschke, A., Djamei, A., Bitton, F., and Hirt, H. (2009). A major role of the MEKK1-MKK1/2-MPK4 pathway in ROS signalling. Mol. Plant 2, 120-137. doi: $10.1093 / \mathrm{mp} / \mathrm{ssn} 079$

Polge, C., and Thomas, M. (2007). SNF1/AMPK/SnRK1 kinases, global regulators at the heart of energy control? Trends Plant Sci. 12, 20-28. doi: 10.1016/J.Tplants.2006.11.005

Price, A. M., Aros Orellana, D. F., Salleh, F. M., Stevens, R., Acock, R., BuchananWollaston, V., et al. (2008). A comparison of leaf and petal senescence in wallflower reveals common and distinct patterns of gene expression and physiology. Plant Physiol. 147, 1898-1912. doi: 10.1104/pp.108.120402

Rogers, H. J. (2012). Is there an important role for reactive oxygen species and redox regulation during floral senescence? Plant Cell Environ. 35, 217-233. doi: 10.1111/J.1365-3040.2011.02373.X

Rogers, H. J. (2013). From models to ornamentals: how is flower senescence regulated? Plant Mol. Biol. 82, 563-574. doi: 10.1007/s11103-012-9968-0

Ryu, S. B., and Wang, X. (1995). Expression of phospholipase D during castor bean leaf senescence. Plant Physiol. 108, 713-719.

Savoure, A., Hua, X. J., Bertauche, N., Van Montagu, M., and Verbruggen, N. (1997). Abscisic acid-independent and abscisic acid-dependent regulation of proline biosynthesis following cold and osmotic stresses in Arabidopsis thaliana. Mol. Gen. Genet. 254, 104-109. doi: 10.1007/s004380050397

Signorelli, S., Arellano, J. B., Melo, T. B., Borsani, O., and Monza, J. (2013). Proline does not quench singlet oxygen: evidence to reconsider its protective role in plants. Plant Physiol. Biochem. 64, 80-83. doi: 10.1016/j.plaphy.2012.12.017

Signorelli, S., Coitino, E. L., Borsani, O., and Monza, J. (2014). Molecular mechanisms for the reaction between $\mathrm{OH}$ radicals and proline: insights on the role as reactive oxygen species scavenger in plant stress. J. Phys. Chem. B 118, 37-347. doi: 10.1021/jp407773u

Sinha, A. K., Jaggi, M., Raghuram, B., and Tuteja, N. (2011). Mitogen-activated protein kinase signaling in plants under abiotic stress. Plant Signal. Behav. 6, 196-203. doi: 10.4161/psb.6.2.14701

Smart, C. M. (1994). Gene expression during leaf senescence. New Phytol. 126, 419-448. doi: 10.1111/j.1469-8137.1994.tb04243.x

Sorkheh, K., Shiran, B., Khodambashi, M., Rouhi, V., Mosavei, S., and Sofo, A. (2012). Exogenous proline alleviates the effects of $\mathrm{H}_{2} \mathrm{O}_{2}$-induced oxidative stress in wild almond species. Russ. J. Plant Physiol. 59, 788-798. doi: 10.1134/S1021443712060167

Strizhov, N., Abraham, E., Okresz, L., Blickling, S., Zilberstein, A., Schell, J., et al. (1997). Differential expression of two P5CS genes controlling proline accumulation during salt-stress requires $\mathrm{ABA}$ and is regulated by $\mathrm{ABA} 1$, ABI1 and AXR2 in Arabidopsis. Plant J. 12, 557-569. doi: 10.1046/j.1365313X.1997.00537.x

Szabados, L., and Savoure, A. (2010). Proline: a multifunctional amino acid. Trends Plant Sci. 15, 89-897. doi: 10.1016/j.tplants.2009.11.009

Szekely, G., Abraham, E., Cseplo, A., Rigo, G., Zsigmond, L., Csiszar, J., et al. (2008). Duplicated P5CS genes of Arabidopsis play distinct roles in stress regulation and developmental control of proline biosynthesis. Plant J. 53, 11-28. doi: 10.1111/j.1365-313X.2007.03318.x

Thiery, L., Leprince, A. S., Lefebvre, D., Ali Ghars, M., Debarbieux, E., and Savoure, A. (2004). Phospholipase D is a negative regulator of proline biosynthesis in Arabidopsis thaliana. J. Biol. Chem. 279, 14812-14818. doi: 10.1074/Jbc.M308456200

Tome, F., Nagele, T., Adamo, M., Garg, A., Marco-Ilorca, C., Nukarinen, E., et al. (2014). The low energy signaling network. Front. Plant Sci. 5:353. doi: 10.3389/Fpls.2014.00353

van Doorn, W. G., and Woltering, E. J. (2004). Senescence and programmed cell death: substance or semantics? J. Exp. Bot. 55, 2147-2153. doi: $10.1093 / \mathrm{Jxb} / \mathrm{Erh} 264$

Verbruggen, N., and Hermans, C. (2008). Proline accumulation in plants: a review. Amino Acids 35, 753-759. doi: 10.1007/s00726-008-0061-6 
Wang, C. Y., Cheng, S. H., and Kao, C. H. (1982). Senescence of rice leaves. 7. Proline accumulation in senescing excised leaves. Plant Physiol. 69, 1348-1349. doi: 10.1104/Pp.69.6.1348

Yakimova, E., Atanassova, B., and Kapchina-Toteva, V. (1997). Longevity and some metabolic envents in postharvest spray-SPRAY-carnation (D. Caryophyllus $F$. sapry, Hort) Flowers. Bulg. J. Plant. Physiol. 23, 57-65.

Zarse, K., Schmeisser, S., Groth, M., Priebe, S., Beuster, G., Kuhlow, D., et al. (2012). Impaired insulin/IGF1 signaling extends life span by promoting mitochondrial L-proline catabolism to induce a transient ROS signal. Cell Metab. 15, 451-465. doi: 10.1016/j.cmet.2012.02.013

Zhang, L., Alfano, J. R., and Becker, D. F. (2015). Proline metabolism increases katG expression and oxidative stress resistance in Escherichia coli. J. Bacteriol. 197, 431-440. doi: 10.1128/JB.02282-14

Zhang, X., Wang, L., Xu, X., Cai, C., and Guo, W. (2014). Genome-wide identification of mitogen-activated protein kinase gene family in Gossypium raimondii and the function of their corresponding orthologs in tetraploid cultivated cotton. BMC Plant Biol. 14:345. doi: 10.1186/s12870-014-0345-9
Zhang, Z., Li, G., Gao, H., Zhang, L., Yang, C., Liu, P., et al. (2012). Characterization of photosynthetic performance during senescence in stay-green and quick-leaf-senescence Zea mays L. inbred lines. PLoS ONE 7:e42936. doi: 10.1371/journal.pone. 0042936

Conflict of Interest Statement: The authors declare that the research was conducted in the absence of any commercial or financial relationships that could be construed as a potential conflict of interest.

Copyright (C) 2015 Zhang and Becker. This is an open-access article distributed under the terms of the Creative Commons Attribution License (CC BY). The use, distribution or reproduction in other forums is permitted, provided the original author(s) or licensor are credited and that the original publication in this journal is cited, in accordance with accepted academic practice. No use, distribution or reproduction is permitted which does not comply with these terms. 